\title{
HIPPOTHERAPY OF CHILDREN WITH DOWN SYNDROME: DIFFICULTIES, RECOMMENDATIONS FOR WORK
}

\author{
Monika Czerw \\ Jan Długosz Academy in Czestochowa, Poland
}

\begin{abstract}
There are many forms of therapy for children with Down syndrome. Among them, hippotherapy is gaining more and more scientific recognition in Poland. Hippotherapy represents an alternative form of rehabilitation, with a key link being an adequately trained horse. The major benefit of hippotherapy is a broad spectrum of effect. It is important for the rehabilitation of people with Down syndrome that hippotherapy offers great opportunities to stimulate physical, cognitive, sensory and verbal areas. Its effect on social functioning of the individual is also substantial. Attractive forms of the therapeutic sessions, positive results of hippotherapeutic effects and the increasing popularity represent the motivation for both practitioners and scholars for organization of knowledge and limitation of scepticism about this field of science.

This paper presents author's observations collected over many years of work as a hippotherapist with people with disabilities. It is aimed to bring closer the aspect of using hippotherapy in the work with children with Down syndrome. The paper also stresses the difficulties and methods to overcome them. It identifies the risks and the observed successes.
\end{abstract}

Keywords: hippotherapy, rehabilitation, Down syndrome.

\section{Introduction}

Patients with various dysfunctions, including those with Down syndrome, and their families, often have to choose one of the rehabilitation methods. The determinants of this choice may vary, from access to the resources of modern rehabilitation and financial status through to personal interests of the person. Among the currently popularized forms of rehabilitation, hippotherapy is gradually gaining popularity, with the main therapeutic link being an animal (horse).

A positive dimension of the relation between human and horse was already found in ancient times. These animals were used for pulling carts. They were also used for land cultivation or transportation (Faiure \& Swift, 2007). The therapeutic values of the relations with horses were already emphasized in ancient times. In the 5th century BC, Hippocrates indicated the relationships between horse riding and treatment of certain diseases (Ustjan \& Jeziorska, 2008). Later, the list of 
benefits was extended to cognitive, social and emotional areas of human development.

\section{Hippotherapy as an alternative form of rehabilitation}

The development of hippotherapy observed in Poland was the inspiration for systematization of the knowledge in this field. The Polish Hippotherapeutic Society (PTHip) established in 1992, which associates experts from various domains, developed the fundamentals for Polish hippotherapy. It should be emphasized that presentation of all aspects which are of key importance to the understanding of the idea of hippotherapy is impossible in this study, since the scope of knowledge in this area is extensive. Therefore, the focus of this text was on the fundamentals of selected aspects of hippotherapeutic effects with consideration for the idea of disability resulting from Down syndrome.

It seems significant to indicate the definition of the term hippotherapy which has been widely used in Poland. It says that hippotherapy should be understood as an "oriented therapeutic activity that should be aimed at the improvement in human functioning in physical, emotional, cognitive and/or social areas, with a specifically trained horse representing an integral part of the therapeutic process" (Strumińska, 2007). It should be noted that this concept in Poland is understood slightly wider than in other countries, where the aspect of physical rehabilitation seems to be somehow more accentuated (see Heipertz-Hengst, 1997). PTHip considers the hippotherapy effects on other areas of human functioning as equally important. This results not only from the above presented definition, adopted canons of Polish hippotherapy and the training curricula for future hippotherapists.

While discussing the problem of hippotherapy at least shortly, one should list the forms distinguished in its area. Analysis of the literature indicates their several classifications. Attempting to find a classification with the highest accuracy would be futile. Regardless of the studies in this area, the hippotherapy distinguishes between: (1) equine physiotherapy, focused on the improvement of motor function. Two models of therapeutic effects are used in equine physiotherapy: (a) neurophysiological, with the key factor being proper sitting position and correctly performed movements and (b) functional, used in children older than 5 years, where improved function is what matters the most; (2) therapy through contact with horse, based on the contact of the patients with the horse. It also happens that the participants of the therapy do not ride a horse at all. In this case, the attempts are made to start and maintain positive relations with the horse and hippotherapist in order to convey it to the further environment and (3) the psychopedagogical horse riding. This form of hippotherapy requires specific physical fitness from participants such that the person is able to sit in the saddle 
and control the horse's movement. The therapeutic sessions also include elements of horse grooming and working in a stable (Strumińska, 2007; Ustjan \& Jeziorska, 2008; Gasińska et al., 2004).

There are also other types of therapy: (4) therapy by horse movement, when the participant is subjected only to horse movements (Kazimierczuk, 2015). In this therapy, the important factor is to transfer the stimuli from the horse to the rider's body and to establish a correct gait patterns in the human brain; (5) horse riding for the disabled. This type often represents a continuation of the previous therapeutic effects. The aim of such a therapy is to instil a habit of active lifestyles, with the most spectacular effects being participation in equine competitions (Strumińska, 2007).

These forms of therapies are interrelated. This improves the efficiency and attractiveness of hippotherapy. All these types can be successfully used in people with Down syndrome. In many cases (if there are no medical contraindications) the hippotherapeutic effects are used in combination with psychopedagogical horse riding. However, it occurs that as a result of the dysfunctions, the use of this form of classes is possible only after several years. Such situations are well demonstrated by the case of 13-year-old Magda. The girl was born with Down syndrome and mild intellectual disability. An additional problem was disturbances in visual-motor coordination and orientation in the child's own body schema. This led to the difficulties with the posting trot (riders' lifting in the saddle during the horse's trot). Magda learnt this ability after 3 years.

It should be emphasized that depending on the needs of a patient, one forms of hippotherapy will dominate over others. This means merely the tendency rather than total elimination (unless health status of the patient suggests the elimination) of some of these forms.

The correctness of the choice is one of the factors that determines the efficiency of hippotherapy. Other factors include a properly trained and chosen horse (in general, the principle of „,small human = small horse” is used), properly adjusted equipment (e.g. conventional saddle, hippotherapeutic saddle, which is rarely used in the case of people with Down syndrome, vaulting belts). Furthermore, it is important to use didactic resources and ensure regular participation in the sessions and engagement of both the hippotherapist and the participant.

Hippotherapy is recommended in rehabilitation of many disturbances. Their list, accepted by PTHip, is very long. Three groups of indications were mentioned by the organization, including Down syndrome. This disability (similar to autism, behaviour disturbances, intellectual disability, depressions etc.), is numbered among the group of recommendations, termed other development disturbances. There are two other groups of disturbances where hippotherapy can be recommended: neurological syndromes (e.g. cerebral palsy, brain microdamages, 
muscle diseases etc.) and orthopaedic syndromes e.g. postural disorders, scoliosis, conditions following amputations, congenital limb defects, muscle contractures (Ustjan \& Jeziorska, 2008).

One should emphasize a broad range of contraindications for participation in this form of therapeutic sessions. Among them are those which entirely disqualify from using hippotherapy and those which need additional expert consultations (so-called relative contraindications). The first group includes e.g. being allergic to horse hair coat and sweat, lack of acceptance of this form of treatment, detachment of the eye retina, lack of control of the head in the motor development or unhealed wounds. Furthermore, the relative contraindications include e.g. frequent epileptic seizures, profound intellectual disability or some vision problems (Ibidem).

In the case of relative indications, the decision on the participation in the therapy depends on the hippotherapist. One example is the aforementioned epileptic seizures. As demonstrated by the examinations among children with Down syndrome, prevalence of the seizures is ca. 1-10 \% (Bhalla et al., 2011). Types of seizures and their frequency may impact on the decisions made by the hippotherapist. It happens that the only form is the therapy through contact with horse. This is not always satisfactory for both participants and their guardians. This was the case with Ania, a 14-year-old girl with Down syndrome, who was substantially overweight and suffered from frequent convulsive seizures. Lack of acceptance of the recommended form of therapy (therapy through contact with horse) determined the refusal to admit the child to hippotherapy. Ania's parents considered hippotherapy as only horse riding.

The specific nature of the therapy (the horse is only an animal, which can be startled, jump to the side, which can lead to the fall) determines the limitations of safety. The likelihood of convulsive seizures additionally increases the risk of dangerous situations. The hippotherapist with small body build is exposed at higher risk of catching the falling rider in case of emergency or if the rider has to dismount the horse (in such situations, the hippotherapist's body acts as a tumbling mat to cushion the fall).

Hippotherapy has a positive effect on many aspects of human life (Ustjan \& Jeziorska, 2008; Strumińska, 2007). From the standpoint of the function of patients with Down syndrome, in addition to the physiological benefits, the most significant advantages include normalization of the muscular contraction, improvement in balance and correcting body posture, returning the disturbed symmetry of body trunk muscles, developing locomotor abilities, stimulation of senses, stimulation of superficial and deep sensation, activation and supporting the work of internal organs. It should also be noted that the general improvement in physical fitness of the individual is also conducive to optimization of social functioning. 
Accordingly, correctly adjusted and designed hippotherapeutic sessions stimulate the development of non-verbal communication, stimulate development of emotional ties, help the patient get used to physical contact and develop subjectivity and responsibility. They positively affect the development of the abilities to start and maintain contacts (Ibidem). In the case of people with Down syndrome, the use of potential of the hippotherapy allows for additional gradual elimination of oppositional and destructive behaviours, tenacity or difficulties in controlling moods. Furthermore, sessions with the horse which does not always obey the instructions develop patience and persistence. The successes are the opportunity to being proud and improve the self-esteem.

Hippotherapy has also benefits in terms of psychological effects. These include in particular stimulation/motivation for action, ensuring emotional security (horse accepts us unconditionally), opportunities of relaxing, providing the feeling of empowerment and practising attention and concentration (Ibidem).

The above mentioned list of benefits is incomplete. Creation of this type of list seems to be disputable. It is worth emphasizing that each participant of hippotherapeutic classes derives specific benefits. Multifaceted nature of the above effects does not make the hippotherapy as superior to other rehabilitation methods. Hippotherapy should be approached as an additional method that supports classical forms of rehabilitation.

\section{Hippotherapy in working with children with Down syndrome: difficulties, recommendations for work}

The below description of the difficulties and suggested solutions, which represents the supplementation of the first part of this study is incomplete. It would be difficult to present all the possible obstacles, guidelines and dilemmas. The author did not intend to develop a comprehensive compendium of knowledge in this area but only to emphasize the complexity of the problem discussed.

Most of the problems encountered during hippotherapy of people with Down syndrome results from their health problems. Among them are e.g. asymptomatic or symptomatic (atlantoaxial) instability of the cervical vertebra, respiratory difficulties, muscle flaccidity, joint hypermobility, postural disorders, or overweight (Cunningham, 1994). However, this does not mean that all of them relate to each patient with Down syndrome.

These medical problems often require additional expert consultation (as mentioned before). Accordingly, due to the instability of the cervical vertebra often observed in people with Down syndrome, it is necessary to take take X-ray images of the cervical spine and provide the hippotherapist with the opinion from the orthopaedist. Working with patients with diagnosed asymptomatic instability requires a particular carefulness during the therapeutic sessions. This forces 
adequate organization and adjustment of the exercise/tasks to individual participants.

In an 11-year-old Adam with such a diagnosis, it was necessary to eliminate trot due to the lack of full control of postural muscles. In order to avoid sudden jumping off the horse's back, dismounting the horse was supported by a specially designed landing. In the case of Adam, it was difficult to explain the boy why he could not start learning to trot. The refusal often led to bursts of angers and the boy had difficulties in controlling them. It was necessary to introduce other exercises or forms of therapy which would be equally attractive and provide the child with sense of satisfaction. One of the proposed solutions was to organize, from time to time, the trip on a horse's back outside the area of the stud farm.

The symptomatic instability allows for participation not only in the therapy through contact with horse. Non-meeting the guidelines can impact on the patient's health and, in extreme cases, can lead even to death. In the case of the lack of medical documentation, the hippotherapist should refuse to accept the child for therapy. The comment of one of the mothers was both unpleasant and dangerous for the child. When asked for providing the medical documents, she ignored the request by saying „I don't have it and don't know when I will... If you don't like it, we will go anywhere else... Stop making issues out of such stupid things!".

People with Down syndrome have tendencies for breathing with their mouth. This is the consequence of the specific build of the skull, substantial palatine tonsils, clogged sinuses or flaccidity of the tongue and mandible muscles (Cunningham, 1994). This increases susceptibility to infections, especially if the weather is worse. The conditions typical of therapeutic sessions i.e. open space or a hall, can additionally increase the incidence of illnesses.

Cancelling therapeutic sessions caused by bad weather or illness limits the opportunities for obtaining positive effects. It is important to ensure the continuity and regularity of the sessions. In this light, one should care for proper clothes. It is worth to have an additional pair of gloves, cap or balm for chapped lips in the autumn and winter periods. Indoors, the difficulties can be caused by dust and dry air. It is worth to remember that before the session (if it is necessary), the hall should be prepared by e.g. watering, which limits the amount of the dust. Unfortunately, some stud farms that offer hippotherapeutic classes fail to offer indoor halls. This is due to limited financial resources.

Hippotherapy is conducive to elimination of postural problems, which in patients with Down syndrome occur quite often due to their overweight and muscle flaccidity. It is critical to ensure proper position on the horseback, with the key importance from the rider's pelvis positions. During the horse's walk (the slowest horse's motion), three-dimensional impulses from the horse's back are transferred to the child's body. The rhythmical gait of the animal helps establish 
proper postural patterns and is conducive to normalization of muscular tension. The hippotherapist determines which muscle group should be trained. Changes in the direction of riding, stopping and starting, changes in the pace and walk or riding a horse on a turn are conducive to the development of the above abilities.

In children with Down syndrome who are able to sit firmly on the horseback, the proper posture is often practised by various climbs or overcoming the obstacles put on the ground. In the initial phase of a climb, body trunk is bent and it returns to its upright position after the downwards movement. In order to stimulate maintaining the body trunk symmetry, one should limit riding to straight lines. Lateral postural control can be developed by riding a slalom along the cones arranged in the indoor manege or around the vehicle tyres arranged in an outdoor obstacle course.

It should also be noted that proper exercises represent merely one aspect of working on proper body posture of the child. Various techniques of correcting and stimulating of the demanded posture are used during the therapeutic sessions. Hand pressure to the spine is used to stimulate the extension, with the hand moved along the spine in the upward direction. Manual correction can be also used, with pressure to the sacral region or the abdomen of the rider. After some time, correction of the rider's position requires only a verbal instruction e.g. „Krzysiu, straight back!”. An attractive activity for children is playing with the rag bag filled with rice and located on the top of the head so that it does not falls off during riding (this exercise should be performed with due care in the case of asymptomatic atlantoaxial instability so that the hyperextension of the cervical region of the spine is prevented).

The aforementioned muscle flaccidity and joint hypermobility (so-called loose joints) make it difficult to ensure proper orientation in the body scheme. The animal movement and additional exercises are of great help. During the horse's movement, impulses from the animal's back are moved to human body. Individual body parts of a rider are moved with respect to each other in space, which has a stimulatory effect on the disturbed functions. Horse's back represents an additional source of stimulants, not only for superficial but also for deep sensation. This is essential for proper development of orientation in person's own body scheme. Furthermore, various stud farm facilities and equipment can be used as therapeutic resources. The only limitations include safety and imagination.

For example, playing with oats can be used to stimulate superficial sensation and senses of the child with Down system. Wading in the shallow pool filled with oats represents a perfect method to ensure multifaceted stimulation. Grains have their specific smell. It is also possible to taste them. Children can bury their hands or feet in the grains. The grains can be tipped from one hand to the other.

Lower physical fitness results from muscle and joint dysfunction and disturbed body height-to-weight ratio. Light or moderate obesity is observed in 
many people with Down syndrome. Therefore, any activity taken in the stud and activities performed with the horse or near the horse are recommended as they can improve general physical capacity of the individual. Cleaning the horse and simple stud chores are approached as a form of playing while encouraging the patient to move. The likelihood of cardiovascular problems should be taken into consideration in children with Down syndrome. However, in the many-year practice of the author, it has never happened that a child, after the cardiological consultation, had to abandon hippotherapy. A hippotherapist should however remember that the exercise should be adjusted to the child's abilities.

Hippotherapy also develops the sense of responsibility and conscientiousness. It improves self-esteem and self-confidence. It helps people be proud of performing the tasks. Furthermore, the stud is a place which forces adjustment to concrete principles, at least for the safety reasons. For example, it is forbidden to move directly behind the horse's rear as the horse can kick the person. Shouting is also forbidden. The box stall can be entered only with hippotherapist and if the horse is facing forward the person. This helps develop the ability to be subordinate. Hippotherapy also provides good conditions to developing the ability to control emotions and eliminate malicious behaviours, which is important to social function of people with Down syndrome (and other diseases).

Furthermore, the abilities to cooperate and compete with others are also developed. Group classes are a perfect solution to develop such competencies. An attractive alternative for the winter season are sleigh rides. During such classes, the group prepares the horse team. The therapist distributes the duties. Individual tasks are assigned to each child. Such activities are often joined by parents. This is conducive to making friends and exchanging views and experiences.

Apart from health problems, another group of difficulties is defensive mechanisms. Therefore, hippotherapist should pay more attention to the emotional status of the participants. Difficult behaviours of the patients are often aimed at the hippotherapist. They represent the result of accumulated emotions. It is necessary that the hippotherapists ensures the atmosphere of acceptance and verbalizes difficult experiences of the patients. The communication such as I understand that you can be afraid, I guess you are offended help work on defensive mechanisms. They also help move to a more constructive work (Jeziorska \& Ustjan, 2009).

Below is an example of the denial mechanism used by 9-year-old Wojtek. The boy was admitted to hippotherapy because of Down syndrome. Wojtek liked one horse very much. Unfortunately, for health reasons, the animal had to be excluded from classes for a certain time. It seemed that the boy accepted the situation. He greeted his favourite horse and started classes on the other. Asked if he was sad, the boy answered in the negative. During several next meetings the 
boy incessantly compared the new horse to his favourite. After some time, when he could participate again in therapeutic sessions on his favourite horse, a noticeable change in his behaviour was observed. He was less diligent during cleaning the horse, tore the horse's mane or reins. When he was angry if the horse did not follow his instruction, Wojtek hit the animal. Asked if he does not like the horse any more, the boy denied. Unfortunately, the behaviour did not change. This changed after the conversation that depicted a fictional situation that referred to the previous events. This was the beginning for further conversations with Wojtek about his anger at the animal.

Hippotherapists can also face other difficulties (due to the type of disability or dysfunction) to be overcome, including fear. The best case is if the participant communicates the fear. This reflects proper relations and mutual trust. The hippotherapists should be able to see such forms of communication as non-verbal signals (crying, escape, hiding hands from the horse). This suggests proper relations, lack of trust and feeling of security. Unfortunately, it happens that instead of accepting the child's fear, rewarding the child verbally and support any attempts to start contact with the animal, the therapist reinforces negative emotions. Therefore, one should avoid punishing (If you don't back the horse, we will have to finish the classes) and such statements as: You shouldn't be afraid, big boys are not afraid; make up your mind - do you back the horse or not? etc. It is worth to use verbal encouragement and show the method of performing specific activities or gradually help child get used to being near the horse (Jeziorska \& Ustjan, 2008).

An example of stages in accustoming the child to the presence of the horse is seven-year-old Majka with Down syndrome. The girl was very happy to see the horse. She waved to the animal, brought various treats and was willing to observe the horse and was willing to draw. Asked whether she wanted to stroke the horse, the girl nodded. However, when she was to approach the animal in order to do this, she hid behind her mother's back and responded with crying. Unfortunately, mother's reactions were negative, which made the situation even worse. The problem could be solved by individual steps: playing and talking using the toy horses, soft rocking horse, observation of other children who cleaned horses and mother on the horse's back to become the model to be followed.

The scope of the difficulties and proposed solutions demonstrates how extensive is this problem. Vast knowledge and skills required from hippotherapists are likely to have initiated the tendency for their specialization in the field of a specific disorder. Addressing hippotherapeutic activities to a concrete group of patients allows for the development of the therapist's own methodologies, collecting necessary resources and equipment and starting a close cooperation with the environment of specialists in the specific field. This is useful from the standpoint of participants as the effectiveness of the therapy can be 
increased. It is worth modifying the training programs for future hippotherapists so that concrete groups of recipients of the classes offered are chosen at specific stages of education.

It should also be emphasized that there are no guidelines in Polish scientific sources concerning methodologies of therapies for people with Down syndrome or other disabled children. One exception is the study by A. Strumińska focused on the people with intellectual disability (Strumińska, 2007). This can be due to the financial limitations that make it difficult to perform multifaceted examinations in this field.

Financial limitations are also emphasized by hippotherapeutic centres and stud farms that offer hippotherapeutic sessions and families, for whom costs of child's participation in such activities are often excessively high. Unfortunately, financial support of the state is insufficient, whereas the necessity of caring for the disabled child often forces one parent (usually mother) to give up his or her job. (Czerw-Bajer \& Karpuszenko, 2013).

\section{Conclusions}

Hippotherapy represents the form of therapy that attracts more and more interest and popularity. It is usually treated by the participants as a form of playing. It is more often considered a pleasure rather than coercion. However, it represents an alternative form of therapeutic effects which are supposed to support conventional rehabilitation methodologies. The hippotherapists are required to have in-depth knowledge and individual approach to the patient.

There is still much to be done by researchers in Poland to popularize this type of therapy. Performing the examinations based on the methodological principles should be the starting point for coherent studies that can represent the guidelines for working in this area of therapy.

\section{References}

Bhalla D., Godet B., Druet-Cabanac, M., \& Preux, P-M. (2011). Etiologies of epilepsy: a comprehensive revie. Expert Rev. Neurother 11 (6). Retrieved from https://pdfs.semanticscholar.org/a062/28f1c3951677578703a2a53a3034d00ba1fb.pdf

Czerw-Bajer, M., \& Karpuszenko, E. (2013). Difficulties in functioning of families with disabled children: research report. In: Jbnebová, R. (Ed.) Spolupráce v sociální práci (p. 450). Hradec Králové: Gaudeamus.

Cunningham, C. (1994). Dzieci z zespołem Downa. Poradnik dla rodziców. (pp. 113-137). Warszawa: Wydawnictwa Szkolne i Pedagigiczne.

Faiure, B., \& Swift, P. (2007). Koń. Poradnik opiekuna (p. 10). Warszawa: RM.

Jeziorska, I., \& Ustjan, D. (2008). Strach - wróg czy sprzymierzeniec hipoterapii? Przeglad Hipoterapeutyczny, 2, 7-8. 
Proceedings of the International Scientific Conference. Volume III, May $25^{\text {th }}-26^{\text {th }}$, 2018. 54-64

Jeziorska, I., \& Ustjan, D. (2009). Mechanizmy obronne najczęściej spotykane podczas zajęć hipoterapeutycznych. Przeglad Hipoterapeutyczny, 1, 6-7.

Kazimierczuk, A. (2015). Hipoterapia - leczenie koniem. Retrieved from http://www.rp.pl/artykul/628869-Hipoterapia---leczenie-koniem.html.

Ustjan, D., \& Jeziorska, I. (2008). Hipoterapia. In: Bekasiewicz, N. (Ed.) Czy zwierzęta potrafia leczyć? Terapie $z$ udziałem zwierzat wspomagajace rehabilitacje osób niepetnosprawnych (pp. 155, 157-158, 161-164, 169-173). Warszawa: Fundacja Przyjaciel.

Heipertz-Hengst, Ch. (1997). Nauka jazdy konnej dla osób niepetnosprawnyc. Warszawa: PWRiL.

Strumińska, A. (2007). Definicja hipoterapii i zakres działań hipoterapeutycznych. In: Strumińska, A. (Ed.) Psychopedagogiczna aspekty hipoterapii dzieci i młodzieży niepelnosprawnych intelektualnie (pp. 17-20, 112-192). Warszawa: Państwowe Wydawnictwo Rolnicze i Leśne.

Strumińska, A. (2007). Hipoterapia - definicja, kanony, etyka. Przegląd Hipoterapeutyczny, 2, 2-3. 